\title{
Retinal venous pressure is decreased after anti-VEGF therapy in patients with retinal vein occlusion-related macular edema
}

\author{
Teruyo Kida ${ }^{1}$ (1) $\cdot$ Josef Flammer $^{2} \cdot$ Katarzyna Konieczka $^{2} \cdot$ Tsunehiko Ikeda $^{1}$
}

Received: 28 October 2020 / Revised: 7 December 2020 / Accepted: 28 December 2020 / Published online: 15 January 2021

(C) The Author(s) 2021

\begin{abstract}
Purpose The pathomechanism leading to retinal vein occlusion (RVO) is unclear. Mechanical compression, thrombosis, and functional contractions of veins are discussed as the reasons for the increased resistance of venous outflow. We evaluated changes in the retinal venous pressure (RVP) following intravitreal injection of anti-vascular endothelial growth factor (VEGF) agent to determine the effect on RVO-related macular edema.

Methods Twenty-six patients with RVO-related macular edema (16 branch RVOs [BRVOs] and 10 central RVOs [CRVOs], age $72.5 \pm 8.8$ years) who visited our hospital were included in this prospective study. Visual acuity (VA), intraocular pressure (IOP), central retinal thickness (CRT) determined by macular optical coherence tomography, and RVP measured using an ophthalmodynamometer were obtained before intravitreal injection of ranibizumab (IVR) and 1 month later.

Results Comparison of the BRVOs and CRVOs showed that VA was significantly improved by a single injection in BRVOs $(P<$ 0.0001; $P=0.1087$ for CRVOs), but CRT and RVP were significantly decreased without significant difference in IOP after the treatment in both groups $(P<0.0001)$.

Conclusion The anti-VEGF treatment resulted in a significant decrease in the RVP, but the RVP remained significantly higher than the IOP. An increased RVP plays a decisive role in the formation of macula edema, and reducing it is desirable.
\end{abstract}

Keywords Anti-VEGF - Branch retinal vein occlusion (BRVO) - Central retinal vein occlusion (CRVO) - Macular edema . Ophthalmodynamometer $\cdot$ Retinal venous pressure (RVP)

Teruyo Kida

opt038@osaka-med.ac.jp

1 Department of Ophthalmology, Osaka Medical College, 2-7

Daigaku-machi, Takatsuki, Osaka 569-8686, Japan

2 Department of Ophthalmology, University of Basel, Basel, Switzerland 


\section{Key messages}

- Retinal vein occlusion (RVO) is one of the most common retinal vascular diseases from old times, but the pathomechanism leading to RVO remains unclear.

- In addition to mechanical compression and thrombosis, functional contractions of the veins are also discussed as the reasons for the increased resistance of venous outflow such that the retinal venous pressure (RVP) seems to be increased in patients with RVO.

- We investigated whether anti-VEGF therapy could reduce the RVP in patients with RVO-related macular edema.

- An increased RVP plays a decisive role in the formation of macula edema, and reducing it is desirable.

\section{Introduction}

Branch retinal vein occlusion (BRVO) was first reported by Leber in 1877 [1], and central retinal vein occlusion (CRVO) by Michel in 1878 [2]. While BRVO commonly occurs in relation to arteriovenous crossing in the unilateral eye [3], CRVO is an obstruction of the central retinal vein and is believed to occur in the retrolaminar region of the optic nerve head [4]. Retinal vein occlusion (RVO) is one of the most common retinal vascular diseases from old times, but the pathomechanism leading to RVO remains unclear. The occlusions seem to be induced by an interaction between local and systemic factors [1, 5-8]. In addition to mechanical compression, the vein locally constricts by itself [9-11]. We can observe vascular changes, such as focal venous obstruction or venous narrowing. In addition to mechanical compression and thrombosis, functional contractions of the veins are also discussed as the reasons for the increased resistance of venous outflow such that the retinal venous pressure (RVP) seems to be increased in patients with BRVO and CRVO. Jonas reported that the RVP was significantly higher in eyes with CRVO and BRVO than in normal eyes [12], and Mozaffarieh et al. observed that the RVP is elevated not only in the eye with CRVO but, to some extent, also in the contralateral apparently healthy eye [13].

Macular edema is the major vision-threatening complication associated with RVO, and it often causes vision decline in patients with this disease. An impaired blood-retinal barrier and increased RVP are both involved in the formation of macular edema. The congestion of the vein can lead to local hypoxia, which, in turn, leads to an increase in hypoxia inducible factor-1-alpha (HIF-1) that also increases the expression of the vascular endothelial growth factor (VEGF) and endothelin, both contributing to macula edema $[14,15]$. Anti-VEGF therapy leads to the rapid reduction of macular edema and an improvement in visual function. However, some patients with RVO require the repeated anti-VEGF drug injections. In some recurrent patients, therefore, there might be a possibility that the RVP is not reduced enough even after a single anti-VEGF drug injection. In addition, the measurement of RVP in patients with RVO-related macular edema might be helpful in predicting whether the patient needs more injections.

In this prospective study, we investigated whether antiVEGF therapy could affect the RVP in patients with RVOrelated macular edema. Under clinical conditions, we measured the RVP using an ophthalmodynamometer (Imedos, Jena, Germany) before and after injecting intravitreal ranibizumab (IVR). We measure RVP because we think it contributes to the clinical picture of RVO and because it may become a good follow-up parameter in the future.

\section{Methods}

Twenty-six RVO patients with untreated macular edema (16 BRVOs and 10 CRVOs) were included in this study. Study approval was obtained from the Institutional Review Board at Osaka Medical College (Registration No. 2038-1) and the research adhered to the tenets of the Declaration of Helsinki.

The inclusion criteria of this study were as follows: (1) symptomatic BRVO or CRVO with macular edema; (2) a foveal thickness greater than $250 \mu \mathrm{m}$, as measured by optical coherence tomography (OCT) at the initial visit; and (3) macular edema secondary to RVO, which had never been previously treated. The diagnosis of RVO was based on the findings from fundus examinations and fluorescein angiographies. Eyes with any co-existing ocular diseases, such as age-related macular degeneration, diabetic retinopathy, hypertension retinopathy, or uveitis, were excluded.

At the initial visit, medical history, including disease durations, was obtained from each patient through a medical interview. At the initial examination, each patient underwent comprehensive ophthalmic examinations, which included the measurement of best-corrected visual acuity (VA) using a 
Landolt chart, measurement of intraocular pressure (IOP), and fundus biomicroscopy with a non-contact lens. Digital fundus photography, fluorescein angiography, and OCT examination were also performed after pupil dilation. The RVO present in each case was classified as ischemic if the fluorescein angiography revealed more than 10 disc areas of retinal nonperfusion for CRVO and 5 disc areas for BRVO.

All patients were treated by injection of IVR after their informed consent was obtained. At each visit before IVR and one month after IVR, each patient underwent a comprehensive ophthalmologic examination, including measurement of best-corrected VA, IOP, RVP, and OCT examination.

All values are presented as the mean \pm standard deviation. For statistical analysis, VA measured with a Landolt chart was converted to the logarithm of the minimum angle of resolution (logMAR). Central retinal thickness (CRT) measured with OCT was determined as the average retinal thickness in a 1mm-diameter circular region at the fovea. Student's $t$ tests were used to evaluate changes in the best-corrected VA (logMAR), CRT, and IOP.

\section{Results}

In this study, we report on 26 eyes from 26 different patients with RVO-related macular edema that received treatment with IVR. Table 1 shows the demographic distribution in the present study. Before the treatment, all eyes showed retinal hemorrhage and macular edema associated with RVO. Ischemic RVO was suspected in three patients at the first visit. The total mean age was $72.5 \pm 8.8$, ranging from 50 to 87 years, with $72.4 \pm 7.5$ years for the BRVOs and $72.5 \pm 11.0$ years for the CRVOs. Three patients with normal tension glaucoma (NTG) (two BRVOs and one CRVO) and one primary open-angle glaucoma (POAG) patient with CRVO were included.

Table 1 Demographic distribution and changes of VA, IOP, and RVP in eyes with RVO

\begin{tabular}{llll}
\hline & Total $(n=26)$ & BRVO $(n=16)$ & CRVO $(n=10)$ \\
\hline Age (years) & $72.5 \pm 8.8$ & $72.4 \pm 7.5$ & $72.5 \pm 11.0$ \\
Females/males & $19 / 7$ & $14 / 2$ & $5 / 5$ \\
Pre VA & $0.62 \pm 0.39$ & $0.58 \pm 0.33$ & $0.70 \pm 0.48$ \\
Post VA & $0.38 \pm 0.31$ & $0.32 \pm 0.28$ & $0.46 \pm 0.36$ \\
Pre IOP (mmHg) & $12.4 \pm 2.3$ & $12.3 \pm 2.1$ & $12.6 \pm 2.6$ \\
Post IOP (mmHg) & $12.6 \pm 2.5$ & $12.0 \pm 1.9$ & $13.6 \pm 3.2$ \\
Pre RVP (mmHg) & $40.0 \pm 5.9$ & $38.6 \pm 7.2$ & $42.2 \pm 1.6$ \\
Post RVP (mmHg) & $29.8 \pm 9.0$ & $27.4 \pm 10.2$ & $33.8 \pm 5.1$ \\
\hline
\end{tabular}

$V A$ visual acuity, $I O P$ intraocular pressure, $R V P$ retinal venous pressure, pre before the treatment, post after the treatment
Figure 1 shows the changes of CRT before and after the treatment. The CRT was significantly decreased in every group of the total RVOs, BRVOs, and CRVOs. The mean CRT was significantly decreased from $650.2 \pm 237.4 \mu \mathrm{m}$ before the treatment to $226.1 \pm 72.4 \mu \mathrm{m} 1$ month after the initial injection $(P<0.0001$, Fig. 1$)$. The mean VA was significantly improved from $0.62 \pm 0.39$ before the treatment to $0.38 \pm 0.31$ 1 month after the treatment $(P=0.0004$, Table 1$)$. The mean RVP level was significantly decreased after IVR from $40.0 \pm$ $5.9 \mathrm{mmHg}$ to $29.8 \pm 9.0 \mathrm{mmHg}(P<0.0001$, Table 1 and Fig. 2). There was no significant difference in IOP before and 1 month after the treatment $(P=0.7698$, Table 1$)$. Comparison of the BRVO and CRVO groups separately showed that VA was significantly improved from $0.58 \pm 0.33$ to $0.32 \pm 0.28$ in the BRVO group. In the CRVO group, VA was changed from $0.70 \pm 0.48$ before the treatment to $0.46 \pm 0.361$ month after the IVR $(P=0.1087)$. The mean CRT was $579.3 \pm 166.5 \mu \mathrm{m}$ before the treatment and $196.7 \pm 25.3 \mu \mathrm{m} 1$ month after IVR in the BRVO group, whereas it was $776.2 \pm 298.6 \mu \mathrm{m}$ before the treatment and $278.3 \pm 98.5 \mu \mathrm{m} 1$ month after IVR in the CRVO group. The mean RVP was $38.6 \pm 7.2 \mathrm{mmHg}$ before the treatment and $27.4 \pm 10.2 \mathrm{mmHg}$ after the treatment in the BRVO group, whereas it was $42.2 \pm 1.6 \mathrm{mmHg}$ before the treatment and $33.8 \pm 5.1 \mathrm{mmHg}$ after the treatment in the CRVO group. The CRT and RVP were significantly decreased in both the BRVO and CRVO groups $(P<0.0001$, Figs. 1 and 2). There was no significant difference in IOP before and 1 month after the treatment in both the BRVO and CRVO groups (Table 1). In addition, the RVP in eyes with RVO was higher than the IOP both before and after the treatment.

\section{Discussion}

In this study, a local anti-VEGF treatment for RVO-related macular edema was applied to the eyes of 26 patients. One month later, the CRT and RVP were significantly reduced in both the BRVO and CRVO groups, and VA was significantly improved in BRVO patients. We found that the RVP in eyes with RVO was significantly decreased after IVR. To the best of our knowledge, we are the first to show that an anti-VEGF therapy for RVO-related macular edema decreases RVP.

RVP is reported as a useful parameter in the management of ophthalmic and systemic disorders, such as glaucoma, increased intracranial pressure, RVO, and diabetic retinopathy [16-22]. In general, the RVP in normal eyes almost equals the IOP [23, 24]; however, it is becoming increasingly clear that RVP is often elevated in various diseases, and these are interestingly diseases in which RVOs are more common. In the present study, we showed that the RVP in eyes with RVO was significantly decreased by a single injection of anti-VEGF drug, but the RVP was still higher than the IOP. We need a 
Fig. 1 Changes in central retinal thickness (CRT) before and after treatment. The mean CRT was significantly decreased after treatment $(* P<0.0001$, paired $t$ test)

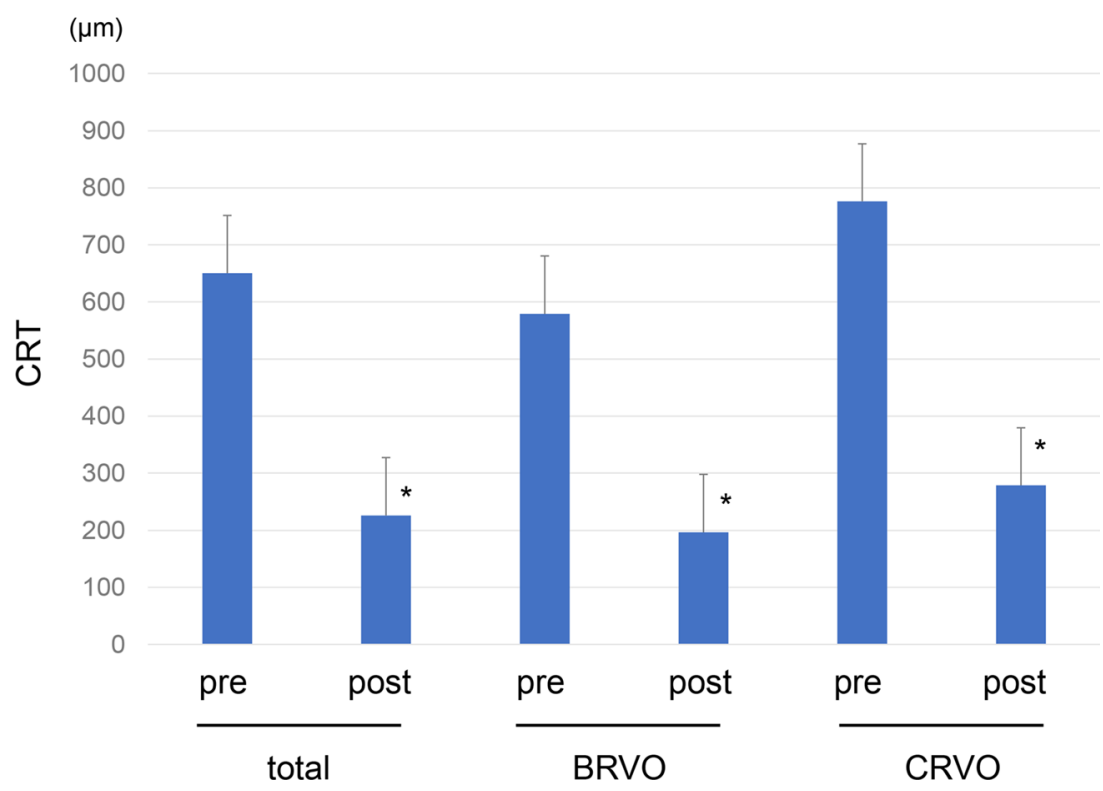

long-term follow-up of RVP changes with the repeated injections.

It is known that a reduction in VEGF normally also leads to a reduction in macular edema with RVO. In the present study, we found that RVP, which is one of the local factors causing RVO, was decreased after anti-VEGF therapy in patients with RVO-related macular edema. As we already know, enhancement of RVP is secondary to RVO, the observation that in patients with RVO the RVP is also elevated in the contralateral eye [13] suggests that this RVP increase cannot only be secondary. It is therefore conceivable that, at least in certain cases, a high RVP precedes RVO and, by contributing to the local hypoxia, contributes to the development of RVO or may even cause it. In relation to systemic factors, lower doses of calcium channel blockers for systemic hypertension than the doses commonly used were found to reduce RVP in patients with retinal vein occlusion [25]. This indicates that systemic hypertension is a well-known risk factor for RVO, and the treatment of systemic hypertension is important for the improvement of RVO-associated macular edema [8]. Another report showed that the degree of RVP elevation was correlated with capillary nonperfusion in patients with severe CRVO [26]. McAllister et al. have also shown that patients with high RVP have a much worse prognosis (e.g., they develop rubeosis more often). Taken together, measuring the RVP in patients with RVO-related macular edema could be a prognostic factor for the recurrence of macular edema.

The pathomechanism of RVO remains unclear. It is known that endothelin-1 (ET-1) plasma is increased in patients with RVO. ET-1 induces constriction of retinal veins, both in vitro
Fig. 2 Changes in retinal venous pressure (RVP) before and after treatment. The mean RVP was significantly decreased after treatment $(* P<0.0001$, paired $t$ test)

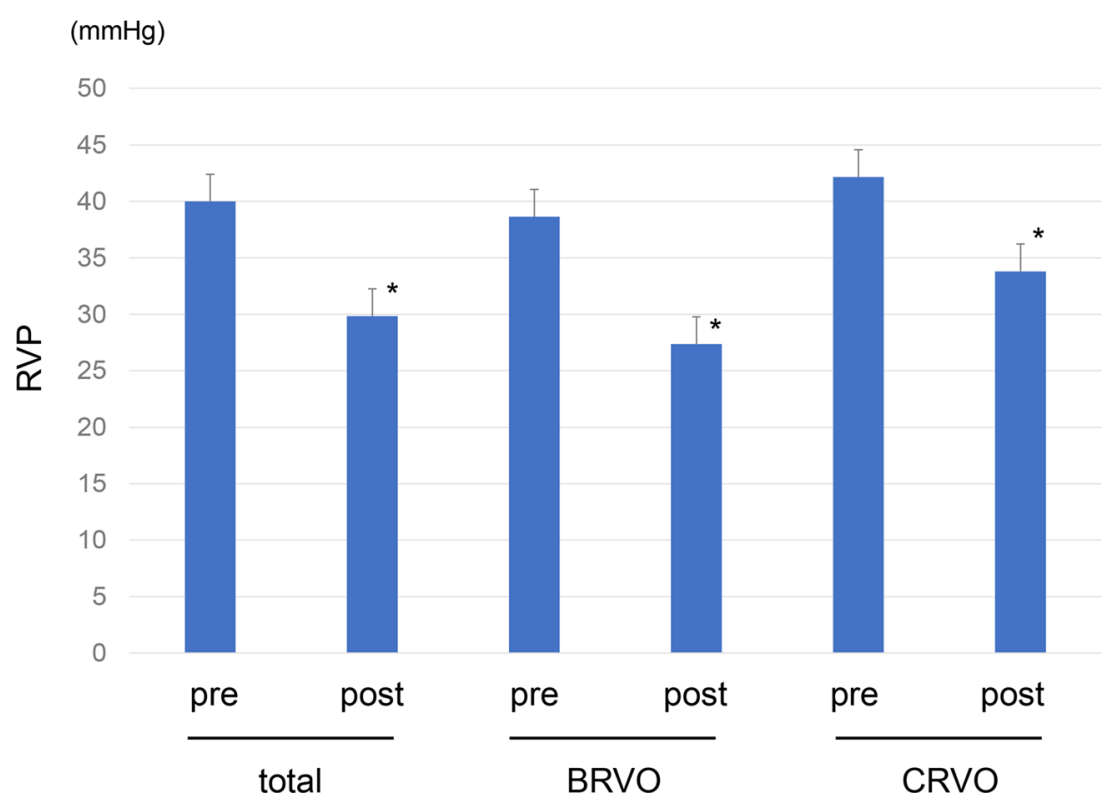


and in vivo, and plays a role in the regulation of RVP [7, 9, 27]. Interestingly, there are interactions between VEGF and ET-1. It has been reported that VEGF stimulates the production of ET-1 [28]. High ET-1 contributes to hypoxia, which, in turn, leads to an increased HIF-1 that increases the coexpression of ET-1 and VEGF [29]. In our previous study, we showed that anti-VEGF drug treatment reduced ET-1 levels in patients with BRVO [30]. Therefore, it is understandable that anti-VEGF therapy in patients with RVO can suppress VEGF and ET-1 levels and then lower the RVP. We recruited patients with RVO-related macular edema in the present study, and their macular edema (measured CRT, Fig. 1) was significantly resolved by anti-VEGF drug. As the RVP increases, the transmural pressure in the capillaries also increases. This increased transmural pressure might lead to macular edema in patients with RVO. If so, lowering the RVP in patients with RVO can also have an important role for macular edema.

This prospective study has some limitations. Its sample size was small, and its follow-up duration was short. Further investigations involving a long-term follow-up with repeated injections of anti-VEGF drug are needed. We also did not measure the VEGF level in intraocular fluid. It would be interesting to see whether the RVP increases again further down the treatment regimen despite ongoing anti-VEGF injections, or if ongoing anti-VEGF causes further lowering of the RVP. In addition, the lowering of RVP that is observed in this study after intravitreal anti-VEGF may be a natural course in eye with retinal vein occlusions, and not a direct effect of antiVEGF treatment. It is known that the RVP naturally decreases with time after retinal vein occlusions without any intervention. To prove our hypothesis, we would need to prospectively compare the RVP in 2 groups of eyes with retinal vein occlusions, one receiving anti-VEGF injections and the other not receiving anti-VEGF injections. This, however, can be an ethical issue to withhold treatment from patients with macular edema. In this prospective study, we indicated that high RVP is possibly involved in the pathogenesis of RVO, and eyes with RVO after IVR showed decreased RVP levels though suppression of intraocular VEGF by anti-VEGF therapy. Moreover, three patients with NTG and one POAG patient with CRVO were included in the present study. We should have measured the RVP also in unaffected eyes so that the RVP in eyes treated with IVR became lower; however, the RVO-unaffected eyes with glaucoma might have remained to have high RVP in above glaucoma patients, as previously reported [20, 24].

In conclusion, we showed that a local anti-VEGF therapy for macular edema in patients with RVO led to a significant decrease in the RVP. An RVP level that is sufficiently suppressed by repeated anti-VEGF therapies or other treatments, such as the improvement of systemic hypertension, is thought to be important for patients with RVO-related macular edema.
Measuring the RVP in eyes with RVO-related macular edema might have the potential to predict the requirements of antiVEGF therapy.

Authors' contributions Conception and design of the study (TK, JF, $\mathrm{KK}$ ); analysis and interpretation (TK, JF); writing of the article (TK); critical revision of the article (TK, JF, TI); final approval of the article (TK, JF, KK, TI); data collection (TK); provision of patients (TK, TI); statistical expertise (JF, KK); literature search (TK, JF); and administrative support (JF, TI).

\section{Compliance with ethical standards}

Conflict of interest The authors declare that they have no conflict of interest.

Ethical approval All procedures performed in studies involving human participants were in accordance with the ethical standards of the institutional and/or national research committee and with the 1964 Helsinki declaration and its later amendments or comparable ethical standards. For this type of study formal consent is not required. The Institutional Review Board (IRB) at the Osaka Medical College Hospital (Registration No. 2038-1) approved the current study.

Open Access This article is licensed under a Creative Commons Attribution 4.0 International License, which permits use, sharing, adaptation, distribution and reproduction in any medium or format, as long as you give appropriate credit to the original author(s) and the source, provide a link to the Creative Commons licence, and indicate if changes were made. The images or other third party material in this article are included in the article's Creative Commons licence, unless indicated otherwise in a credit line to the material. If material is not included in the article's Creative Commons licence and your intended use is not permitted by statutory regulation or exceeds the permitted use, you will need to obtain permission directly from the copyright holder. To view a copy of this licence, visit http://creativecommons.org/licenses/by/4.0/.

\section{References}

1. Jaulim A, Ahmed B, Khanam T, Chatziralli IP (2013) Branch retinal vein occlusion: epidemiology, pathogenesis, risk factors, clinical features, diagnosis, and complications. An update of the literature. Retina 33:901-910. https://doi.org/10.1097/IAE. 0b013e3182870c15

2. Hayreh SS, Podhajsky PA, Zimmerman MB (2011) Natural history of visual outcome in central retinal vein occlusion. Ophthalmology 118: 119-133.e111-112 https://doi.org/10.1016/j.ophtha.2010.04. 019

3. Clemett RS (1974) Retinal branch vein occlusion. Br J Ophthalmol 58:548-554

4. Morley MG HJ (2009) Venous obstructive disease of the retina. In: Yanoff M, Duker JS (eds). Ophthalmology. 3rd edition. Mosby Elsevier, pp 597-605

5. Cheung N, Klein R, Wang JJ, Cotch MF, Islam AF, Klein BE, Cushman M, Wong TY (2008) Traditional and novel cardiovascular risk factors for retinal vein occlusion: the multiethnic study of atherosclerosis. Invest Ophthalmol Vis Sci 49:4297-4302. https:// doi.org/10.1167/iovs.08-1826

6. Cugati S, Wang JJ, Rochtchina E, Mitchell P (2006) Ten-year incidence of retinal vein occlusion in an older population: the Blue 
Mountains Eye Study. Arch Ophthalmol 124:726-732. https://doi. org/10.1001/archopht.124.5.726

7. Fraenkl SA, Mozaffarieh M, Flammer J (2010) Retinal vein occlusions: the potential impact of a dysregulation of the retinal veins. EPMA J 1:253-261. https://doi.org/10.1007/s13167-010-0025-2

8. Kida T, Morishita S, Kakurai K, Suzuki H, Oku H, Ikeda T (2014) Treatment of systemic hypertension is important for improvement of macular edema associated with retinal vein occlusion. Clin Ophthalmol 8:955-958. https://doi.org/10.2147/opth.s63368

9. Yu DY, Su EN, Cringle SJ, Morgan WH, McAllister IL, Yu PK (2016) Local modulation of retinal vein tone. Invest Ophthalmol Vis Sci 57:412-419. https://doi.org/10.1167/iovs.15-18358

10. Kida T, Flammer J, Oku H, Konieczka K, Morishita S, Horie T, Ikeda T (2018) Vasoactivity of retinal veins: a potential involvement of endothelin-1 (ET-1) in the pathogenesis of retinal vein occlusion (RVO). Exp Eye Res 176:207-209. https://doi.org/10. 1016/j.exer.2018.07.016

11. Flammer J, Konieczka K (2015) Retinal venous pressure: the role of endothelin. EPMA J 6:21. https://doi.org/10.1186/s13167-0150043-1

12. Jonas JB (2003) Ophthalmodynamometric assessment of the central retinal vein collapse pressure in eyes with retinal vein stasis or occlusion. Graefes Arch Clin Exp Ophthalmol 241:367-370. https://doi.org/10.1007/s00417-003-0643-7

13. Mozaffarieh M, Bärtschi M, Henrich PB, Schoetzau A, Flammer J (2014) Retinal venous pressure in the non-affected eye of patients with retinal vein occlusions. Graefes Arch Clin Exp Ophthalmol 252:1569-1571. https://doi.org/10.1007/s00417-014-2617-3

14. Campochiaro PA (2015) Molecular pathogenesis of retinal and choroidal vascular diseases. Prog Retin Eye Res 49:67-81. https:// doi.org/10.1016/j.preteyeres.2015.06.002

15. Vinores SA, Youssri AI, Luna JD, Chen YS, Bhargave S, Vinores MA, Schoenfeld CL, Peng B, Chan CC, LaRochelle W, Green WR, Campochiaro PA (1997) Upregulation of vascular endothelial growth factor in ischemic and non-ischemic human and experimental retinal disease. Histol Histopathol 12:99-109

16. Abdul-Rahman A, Morgan W, Yu DY (2020) Measurement of normal retinal vascular pulse wave attenuation using modified photoplethysmography. PLoS One 15:e232523. https://doi.org/ 10.1371/journal.pone.0232523

17. Seo JH, Kim TW, Weinreb RN, Kim YA, Kim M (2012) Relationship of intraocular pressure and frequency of spontaneous retinal venous pulsation in primary open-angle glaucoma. Ophthalmology 119:2254-2260. https://doi.org/10.1016/j.ophtha. 2012.06.007

18. Cybulska-Heinrich AK, Baertschi M, Loesche CC, Schoetzau A, Konieczka K, Josifova T, Flammer J (2015) Patients with diabetic retinopathy have high retinal venous pressure. EPMA J 6:5. https:// doi.org/10.1186/s13167-015-0027-1

19. Lee E, Kim TW, Kim JA, Kim JA, Kim H (2017) Spontaneous retinal venous pulsation in unilateral primary open-angle glaucoma with low intraocular pressure. J Glaucoma 26:896-901. https://doi. org/10.1097/ijg.0000000000000759
20. Pillunat KR, Ventzke S, Spoerl E, Furashova O, Stodtmeister R, Pillunat LE (2014) Central retinal venous pulsation pressure in different stages of primary open-angle glaucoma. Br J Ophthalmol 98: 1374-1378. https://doi.org/10.1136/bjophthalmol-2014-305126

21. Mustur D, Vahedian Z, Bovet J, Mozaffarieh M (2017) Retinal venous pressure measurements in patients with Flammer syndrome and metabolic syndrome. EPMA J 8:339-344. https://doi.org/10. 1007/s13167-017-0105-7

22. Stewart PS, Jensen OE, Foss AJ (2014) A theoretical model to allow prediction of the CSF pressure from observations of the retinal venous pulse. Invest Ophthalmol Vis Sci 55: 6319-6323 https:// doi.org/10.1167/iovs.14-14331

23. Meyer-Schwickerath R, Kleinwachter T, Firsching R, Papenfuss HD (1995) Central retinal venous outflow pressure. Graefes Arch Clin Exp Ophthalmol 233:783-788

24. Morgan WH, Hazelton ML, Yu DY (2016) Retinal venous pulsation: expanding our understanding and use of this enigmatic phenomenon. Prog Retin Eye Res 55:82-107. https://doi.org/10.1016/ j.preteyeres.2016.06.003

25. Fang L, Turtschi S, Mozaffarieh M (2015) The effect of nifedipine on retinal venous pressure of glaucoma patients with the FlammerSyndrome. Graefes Arch Clin Exp Ophthalmol 253:935-939. https://doi.org/10.1007/s00417-015-3001-7

26. McAllister IL, Tan MH, Smithies LA, Wong WL (2014) The effect of central retinal venous pressure in patients with central retinal vein occlusion and a high mean area of nonperfusion. Ophthalmology 121:2228-2236. https://doi.org/10.1016/j.ophtha.2014.05.031

27. Paques M, Brolly A, Benesty J, Lerme N, Koch E, Rossant F, Bloch I, Girmens JF (2015) Venous nicking without arteriovenous contact: the role of the arteriolar microenvironment in arteriovenous nickings. JAMA Ophthalmol 133:947-950. https://doi.org/10. 1001/jamaophthalmol.2015.1132

28. Wu MH, Huang CY, Lin JA, Wang SW, Peng CY, Cheng HC, Tang CH (2014) Endothelin-1 promotes vascular endothelial growth factor-dependent angiogenesis in human chondrosarcoma cells. Oncogene 33:1725-1735. https://doi.org/10.1038/onc.2013. 109

29. Spinella F, Rosanò L, Di Castro V, Natali PG, Bagnato A (2002) Endothelin-1 induces vascular endothelial growth factor by increasing hypoxia-inducible factor-1alpha in ovarian carcinoma cells. $\mathrm{J}$ Biol Chem 277:27850-27855. https://doi.org/10.1074/jbc. M202421200

30. Kida T, Flammer J, Oku H, Morishita S, Fukumoto M, Suzuki H, Konieczka K, Ikeda T (2016) Suppressed endothelin-1 by antiVEGF therapy is important for patients with BRVO-related macular edema to improve their vision. EPMA J 7:18. https://doi.org/10. 1186/s13167-016-0066-2

Publisher's note Springer Nature remains neutral with regard to jurisdictional claims in published maps and institutional affiliations. 